\title{
Causes of Admission and out Comes among Preeclampsia and Eclampsia Mothers Admitted to Jimma University Specialized Hospital Intensive Care Unit
}

\author{
Nega Desalegn, Merga Haile \\ Anesthesia Department, College of Heath Science, Jimma University, Jimma Ethiopia
}

Email address:

nega.desalegn@yahoo.com (N. Desalegn),merga_haile@yahoo.com (M. Haile)

To cite this article:

Nega Desalegn, Merga Haile. Causes of Admission and out Comes Among Preeclampsia and Eclampsia Mothers Admitted to Jimma University Specialized Hospital Intensive Care Unit. Clinical Medicine Research. Vol. 4, No. 5, 2015, pp. 154-159.

doi: 10.11648/j.cmr.20150405.16

\begin{abstract}
Background: Preeclampsia is a multisystem hypertensive disorder of pregnancy with new onset after 20 weeks gestation which is a leading cause of worldwide maternal and fetal morbidity-mortality. Objective: To assess causes of ICU admission and outcomes among pre-eclampsia and eclampsia mothers admitted to Jimma University Specialized Hospital. Methods: A retrospective cross sectional study was conducted at JUSH from May 3 to 8, 2015, all ICU admitted preeclampsia and eclampsia mother's records from January 1, 2010 to December 31, 2014 were included by consecutive sampling with inclusion and exclusion criteria. Causes of admission, complications and outcomes were obtained from patient records and analyzed by SPSS version 16.0, finally the results presented using simple frequency tables and figures. Chi square (x2) test calculated to analyze the statistical association between patients outcome and other variables, $p$-value less than 0.05 was considered statistically significant. Result: A total of 1981 patients admitted to Jimma University specialized hospital ICU over the last five years (January 1, 2010 to December 31, 2014) from this 326 of them were preeclampsia and eclampsia mothers and this gives admission rate of $16.5 \%$. For this study only total of 314 preeclampsia and eclampsia mothers records were used and 12 mothers cards were excluded by exclusion criteria. The main causes of admission to ICU were eclampsia 106 (33.8\%), General condition need close observation 77(24.5\%), pulmonary edema $63(20.1 \%)$, postoperative bleeding 31(9.9\%) While the main complications were pulmonary edema 82(26.1\%), acute renal injury 76(24.2), HELLP syndrome 57(18.2\%) and mortality rate of $7.3 \%$.There is association level of blood pressure with maternal outcomes. Conclusion: Rate of maternal admission, complications and mortality is found to be high at JUSH ICU, Jimma University with other stakeholders has to work in improving high quality of cares provided to reduce maternal complications and mortality.
\end{abstract}

Keywords: Intensive Care, Preeclampsia, Eclampsia, Admission, Complications

\section{Introduction}

Hypertension remains a relatively common medical complication of pregnancy with related disorders affecting up to $12 \%$ of cases. Unlike others, obstetric patients pose a major management challenge to ICU physicians and obstetricians due to altered physiology during pregnancy, consideration of fetal wellbeing, and the unique type of disorders to be dealt with $(1,2)$

Although pregnancy is usually a natural process that proceeds without complication, approximately $0.1-0.9 \%$ of pregnant women will develop critical illness requiring intensive care (3). Obstetric admissions to the intensive care unit (ICU) and maternal mortality continue to have a significant impact on maternal health care, despite the low rate of such admissions in developed countries (4). Unlike others, obstetric patients pose a major management challenge to ICU physicians and obstetricians due to altered physiology during pregnancy, consideration of fetal wellbeing, and the unique type of disorders to be dealt with (5).

Hypertension remains a relatively common medical complication of pregnancy with related disorders affecting up to $12 \%$ of cases. Eclamptic seizures may occur antenatal (38\%), intra-partum (18\%) or post-partum (44\%) (6).

Preeclampsia is a pregnancy specific hypertensive syndrome associated with significant morbidity and mortality in mother and baby. Preeclampsia-eclampsia needs intensive care Antepartum, intrapartum as well as postpartum for 
successful pregnancy outcome. Preeclampsia leads to multiorgan system involvement if appropriate timing of delivery is delayed. (7)

Pre-eclampsia is characterized by the onset of hypertension and proteinuria after 20 weeks gestation in a previously normotensive patient. Abnormal placentation releases circulating factors that cause vascular endothelial dysfunction in the mother, manifesting as hypertension and renal dysfunction (8).

Pre-eclampsia is a multisystem disease process. Two cardinal features must exist in order to make the diagnosis: Presence of sustained hypertension Systolic blood pressure $>140 \mathrm{mmHg}$, Diastolic blood pressure $>90 \mathrm{mmHg}$ and Proteinuria $>300 \mathrm{mg}$ protein in a 24-hour urine collection (9)

Severe pre-eclampsia is more likely to require critical care and is diagnosed by the presence of more severe blood pressure elevation and significant organ dysfunction. Preeclampsia predominantly affects the maternal cardiovascular, neurological and renal systems, but all systems are affected to a greater or lesser degree. The presence of neurological signs and symptoms tend to be indicative of severe preeclampsia. The more common manifestations include: Persistent headache, Visual disturbances, Hyperreflexia and Seizures (indicative of eclampsia until proven otherwise) (10).

Despite the drastic decrease in maternal morbidity over the last few decades because of improvements in obstetric care maternal mortality remains to be a challenge in the developing world. Only a few studies have been published concerning ICU admissions of obstetric patients in the developing world, in which maternal mortality rates have ranged from $28 \%$ to $60 \%(11,12,13)$.

\section{Method and Materials}

The study was conducted at JUSH which is located $346 \mathrm{kms}$ from capital Addis Ababa. Jimma University specialized hospital(JUSH) is one of the oldest public hospital in the country, Currently it become the only teaching and referral hospital in the south western part of the country with bed capacity of 450 and a total of more than 750 staffs of both supportive and professional. Currently the hospital provides medical services like clinical service for approximately 9000 inpatient and 80000 outpatients. ICU department is one of the major inpatient departments that provide services for critically ill patients that accommodate 6 beds with two functioning mechanical ventilators. JUSH ICU is running by two Anesthesiologists, Anesthesiology residents, Internists, Nurses, Medical interns, Residents of surgery and Internal medicine.

Using retrospective cross sectional study from May 3 to 8, 2015 with consecutive sampling a total of 314 preeclampsia and eclampsia mothers' cards who admitted to Jimma University ICU from January 1, 2010 G.C to December 31, 2014 G.C were included by using inclusion and exclusion criteria. Causes of admission, complications and outcomes were obtained from patient records using check list and the collected data was checked at the end of each day for their completeness, and consistency, and it was cleaned manually and analyzed using SPSS version16.0.

Chi square $\left(x^{2}\right)$ test calculated to analyze the statistical association between patients outcome and other variables, $\mathrm{p}$ value less than 0.05 was considered statistically significant.

\subsection{Exclusion Criteria}

Mothers card which doesn't contain either of :outcome, causes of admission, ANC not documented were excluded $(n=12)$

\subsection{Ethical Considerations}

Before the actual data collection process, an official permission letter was obtained from Ethical committee of Jimma University, in addition the brief explanation of the study objective was given for ICU healthcare team, and record keeper workers about the objective of this study and confidentiality of patients' information.

\section{Result}

A total of 1981 patients admitted to Jimma University specialized hospital ICU over the last five years from this 326 of them were preeclampsia and eclampsia and this gives $16.5 \%$ of total admission. For this study only total of 314 preeclampsia and eclampsia mothers records were used and 12 mothers cards were excluded by exclusion criteria. From the total 314 analyzed, about 208(66.2\%) were sever preeclampsia and 106(32.8\%) were eclamtic mothers. About $85(27.1)$ were between $34-38$ years age group and 66(21\%) of them were between 39-43 years age group. More than half of cases $189(60.2 \%)$ were from rural. $228(72.6 \%)$ of them were multigravida and $86(27.4)$ them prim gravida. 149 (47.5) has ANC follow up, about 192(61.1) of them has admission BP of $>170 / 110 \mathrm{mmhg}$. Majority 154(49\%) have $2++$ proteinuria on admission (See Table 1 below). Regarding modes of delivery $253(80.6 \%)$ by cesarean section, among them $133(52.6 \%)$ undergone $\mathrm{C} / \mathrm{S}$ while in labor and $42(13.4 \%)$ the mothers give birth by normal vaginal delivery (Table 2).

Causes of admission: The main causes of admission were sever eclampsia 106 (33.8\%), General condition need close observation 77(24.5\%), pulmonary edema 63 (20.1\%), postoperative bleeding $31(9.9 \%)$ and anesthesia complications $16(5.1 \%)$ (Table 2$)$.

Complications and outcomes: With the mean length of ICU stay of 7.1 days and overall mortality rate of $7.3 \%$, the major complications were pulmonary edema $82(26.1 \%)$, acute renal injury 76(24.2), HELLPsyndrome 57(18.2\%) (Table 2).

\section{Discussion}

Preeclampsia is a multisystem hypertensive disorder of 
pregnancy with new onset after 20 weeks gestation which is a leading cause of worldwide maternal and fetal morbiditymortality (19).

From a total of 314 patients studied, about $85(27.1)$ were between 34- 38 years age group and 66(21\%) of them were between 39-43 years age group. About189 (60.2\%) were from rural, $228(72.6 \%)$ of them were multigravida and 86(27.4) them prim gravida. 149 (47.5) has ANC follow up other study conducted at Argentina has showed that ANC follow up has association with maternal outcomes (14).

Majority 192(61.1) of mothers has admission BP of $>170 / 110 \mathrm{mmhg}$ there is association between admission blood pressure of this mothers with their outcomes $(\mathrm{P}=0.028265)$ this may be due to the higher and unstable blood pressure is associated with vital organ perfusion derangement as many vital organs have autoregulation to maintain their perfusion and high BP is also associated to complications like stroke, myocardial ischemia, renal, ocular problems and even death.

About 154(49\%) have 2++ proteinuria on admission this proteinuria has also association with the maternal out comes $(\mathrm{P}=0.000361)$ this is similar to the study finding from Spain

Table 1. Socio demographic and maternal characteristics, among ICU admitted pre-eclampsialeclampsia patients, JUSH, Jimma town, Southwestern Ethiopia, June 2015.

\begin{tabular}{|c|c|c|}
\hline Variables & & Number (Percent) \\
\hline \multirow{8}{*}{ Age } & $<18$ & $23(7.3)$ \\
\hline & $18-22$ & $32(10.2)$ \\
\hline & $23-27$ & $39(12.4)$ \\
\hline & $28-33$ & $54(17.2)$ \\
\hline & $34-38$ & $85(27.1)$ \\
\hline & $39-43$ & $66(21.0)$ \\
\hline & $\geq 44$ & $15(4.8)$ \\
\hline & Total & $314(100)$ \\
\hline \multirow{3}{*}{ Address } & Rural & $189(60.2)$ \\
\hline & Urban & $125(39.8)$ \\
\hline & Total & $314(100)$ \\
\hline \multirow{3}{*}{ Gravida } & Para gravid & $86(27.4)$ \\
\hline & Multi gravid & $228(72.6)$ \\
\hline & Total & $314(100)$ \\
\hline \multirow{4}{*}{ Parity } & Nulliparous & $86(27.4)$ \\
\hline & Primipara & $97(30.9)$ \\
\hline & Multipara & $131(41.7)$ \\
\hline & Total & $314(100)$ \\
\hline \multirow{3}{*}{ ANC follow up } & Yes & $149(47.5)$ \\
\hline & No & $165(52.5)$ \\
\hline & Total & $314(100.0)$ \\
\hline \multirow{3}{*}{$\begin{array}{l}\text { Blood pressure on } \\
\text { admission }\end{array}$} & $140 / 90-169 / 109$ & $122(38.9)$ \\
\hline & $>170 / 110$ & $192(61.1)$ \\
\hline & total & $314(100)$ \\
\hline \multirow{4}{*}{ Proteinuria on admission } & $2+$ & $58(18.5)$ \\
\hline & $2++$ & $154(49.0)$ \\
\hline & $3+++$ & $102(32.5)$ \\
\hline & total & $314(100)$ \\
\hline \multirow{5}{*}{ Duration of hospital stay } & 3-5days & $35(11.1)$ \\
\hline & 5-10days & $189(60.2)$ \\
\hline & 10-15days & $81(25.8)$ \\
\hline & $>15$ days & $9(2.9)$ \\
\hline & total & $314(100.0)$ \\
\hline
\end{tabular}

reported protein urea and null parity associated with maternal outcomes (15).

Regarding duration of hospital stay majority $189(602 \%) 5-$ 10days with mean ICU stay of 7.1days and duration of hospital stay has strong association with mothers outcome $(\mathrm{p}=0.000464)$ as the death rate among the 3-5days is about $(22.6 \%)$ and $10-15$ days about $(4.9 \%)$ and this shows the longer they stay the better outcome according to this study and vise verse this may be due to many factors like the patients status on admission like their vital signs, consciousness levels and degree of vital organ damage (liver, kidney CVS and lungs).

Regarding modes of delivery $80.6 \%$ of the cases were undergone cesarean section, this rate of $\mathrm{C} / \mathrm{S}$ is almost similar as compared to the study done in Cameroon showed rate of C/S 44 (78.2) (16).

About 52(16.6\%) of the eclampsia cases occurred during antenatal, and $13.1 \%$ occurred post-delivery and this is almost similar to the study done in Yorkshire UK retrospectively reported $55 \%$ for eclampsia cases occurred during antenatal, and $32 \%$ for cases occurred post-delivery (13).

Table 2. Modes of delivery, Causes of admission, maternal complications and outcomes, among ICU admitted pre-eclampsia/eclampsia patients, JUSH, Jimma town, Southwestern Ethiopia, June 2015.

\begin{tabular}{|c|c|c|}
\hline \multicolumn{2}{|c|}{ Types of delivery method } & Number ( Percent) \\
\hline \multicolumn{2}{|c|}{ Cesarean section delivery } & $253(80.6)$ \\
\hline \multicolumn{2}{|c|}{ Normal vaginal deliveries } & $42(13.4)$ \\
\hline \multicolumn{2}{|c|}{ Operative vaginal deliveries } & $19(6.1)$ \\
\hline \multicolumn{2}{|l|}{ Total } & $314(100)$ \\
\hline \multirow{6}{*}{$\begin{array}{l}\text { Causes of ICU } \\
\text { admission }\end{array}$} & Eclampsia & $106(33.8)$ \\
\hline & $\begin{array}{l}\text { General condition requiring } \\
\text { close observation }\end{array}$ & $77(24.5)$ \\
\hline & Pulmonary edema & $63(20.1)$ \\
\hline & Postoperative bleeding & $31(9.9)$ \\
\hline & Anesthesia complications & $16(5.1)$ \\
\hline & Ventilator problem & $21(6.6)$ \\
\hline \multirow{9}{*}{$\begin{array}{l}\text { Maternal } \\
\text { complications } \\
\text { and out comes }\end{array}$} & Pulmonary edema & $82(26.1 \%)$ \\
\hline & Acute renal injury & $76(24.2)$ \\
\hline & HELLP syndrome & $57(18.2 \%)$ \\
\hline & $\begin{array}{l}\text { Coagulation problem(requiring } \\
\text { factor transfusion) }\end{array}$ & $43(13.7 \%)$ \\
\hline & Thromboembolism & $23(7.3 \%)$ \\
\hline & Coma & $21(6.7 \%)$ \\
\hline & Stroke & $9(2.9 \%)$ \\
\hline & Visual problem & $4(1.3 \%)$ \\
\hline & Death & $23(7.3)$ \\
\hline
\end{tabular}


Table 3. Factors associated with maternal outcomes, among ICU admitted pre-eclampsia/eclampsia patients, JUSH, Jimma town, Southwestern Ethiopia, June 2015

\begin{tabular}{|c|c|c|c|c|c|c|c|c|}
\hline \multirow{3}{*}{ Variables } & & \multicolumn{6}{|c|}{ Outcomes } & \multirow[t]{3}{*}{ P-value } \\
\hline & & \multicolumn{2}{|c|}{ Improved } & \multicolumn{2}{|c|}{ Death } & \multicolumn{2}{|c|}{ Total } & \\
\hline & & No. & $\%$ & No. & $\%$ & No. & $\%$ & \\
\hline \multirow{8}{*}{ Age } & $<18$ & 20 & 86.9 & 3 & 13.1 & 23 & 7.3 & \multirow{4}{*}{ NA } \\
\hline & $18-22$ & 28 & 87.5 & 4 & 12.5 & 32 & 10.2 & \\
\hline & $23-27$ & 35 & 89.7 & 4 & 10.3 & 39 & 12.4 & \\
\hline & $28-33$ & 49 & 90.7 & 5 & 9.3 & 54 & 17.2 & \\
\hline & $34-38$ & 81 & 95.2 & 4 & 4.8 & 85 & 27.1 & \multirow{6}{*}{0.9449} \\
\hline & $39-43$ & 64 & 96.9 & 2 & 2.1 & 66 & 21.0 & \\
\hline & $\geq 44$ & 14 & 93.3 & 1 & 6.7 & 15 & 4.8 & \\
\hline & Total & 291 & 92.7 & 23 & 7.3 & 314 & 100 & \\
\hline \multirow{3}{*}{ Address } & Rural & 175 & 92.6 & 14 & 7.4 & 189 & 60.2 & \\
\hline & Urban & 116 & 92.8 & 9 & 7.2 & 125 & 39.8 & \\
\hline & Total & 291 & 92.7 & 23 & 7.3 & 314 & 100 & \multirow{3}{*}{0.4088} \\
\hline \multirow{3}{*}{ Gravida } & Primi gravid & 78 & 90.7 & 8 & 9.3 & 86 & 27.4 & \\
\hline & Multi gravid & 213 & 93.4 & 15 & 6.6 & 228 & 72.6 & \\
\hline & Total & 291 & 92.7 & 23 & 7.3 & 314 & 100 & \multirow{5}{*}{0.17414} \\
\hline \multirow{4}{*}{ Parity } & Nulliparous & 82 & 95.3 & 4 & 4.7 & 86 & 27.4 & \\
\hline & Primipara & 86 & 88.7 & 11 & 11.3 & 97 & 30.9 & \\
\hline & Multi para & 123 & 93.9 & 8 & 6.1 & 131 & 41.7 & \\
\hline & Total & 291 & 92.7 & 23 & 7.3 & 314 & 100 & \\
\hline \multirow{3}{*}{ ANC follow up } & Yes & 133 & 94.8 & 7 & 5.2 & 140 & 44.5 & \multirow{3}{*}{0.1561} \\
\hline & No & 158 & 89.9 & 16 & 10.1 & 174 & 55.4 & \\
\hline & Total & 291 & 92.7 & 23 & 7.3 & 314 & 100.0 & \\
\hline \multirow{3}{*}{ Blood pressure on admission } & $140 / 90-169 / 109$ & 118 & 96.7 & 4 & 3.3 & 122 & 38.9 & \multirow{2}{*}{0.0282} \\
\hline & $170 / 110$ & 173 & 90.1 & 19 & 9.9 & 192 & 61.1 & \\
\hline & total & 291 & 92.7 & 23 & 7.3 & 314 & 100 & \multirow{4}{*}{0.0003} \\
\hline \multirow{9}{*}{ Proteinuria on admission } & $2+$ & 57 & 98.3 & 1 & 1.7 & 58 & 18.5 & \\
\hline & $2++$ & 148 & 96.1 & 6 & 5.9 & 154 & 49.0 & \\
\hline & $3+++$ & 86 & 84.3 & 16 & & 102 & 32.5 & \\
\hline & total & 291 & 92.7 & 23 & 7.3 & 314 & 100 & \multirow{4}{*}{0.1711} \\
\hline & Caesarean section & 234 & & 19 & & 253 & 80.6 & \\
\hline & Normal deliveries & 41 & & 1 & & 42 & 13.4 & \\
\hline & $\begin{array}{l}\text { Operative vaginal } \\
\text { deliveries }\end{array}$ & 16 & & 3 & & 19 & 6.1 & \\
\hline & Total & 291 & 92.7 & 23 & 7.3 & 314 & 100 & \\
\hline & Antenatal & 46 & & 6 & & 52 & 16.6 & \\
\hline \multirow{3}{*}{ Timing of eclampsia cases } & $\begin{array}{l}\text { Before admission to } \\
\text { maternity unit }\end{array}$ & 81 & 90.0 & 9 & 10.0 & 90 & 28.7 & \\
\hline & In labor/delivery & 129 & 98.5 & 2 & 1.5 & 131 & 41.7 & 0.0073 \\
\hline & Post delivery & 35 & 85.4 & 6 & 14.6 & 41 & 13.1 & \\
\hline & Total & 291 & 92.7 & 23 & 7.3 & 314 & 100 & \\
\hline & 3-5days & 27 & 77.4 & 8 & 22.6 & 35 & 11.1 & \\
\hline & 5-10days & 180 & 95.2 & 9 & 4.8 & 189 & 60.2 & \\
\hline Duration of hospital stay & 10-15days & 77 & 95.1 & 4 & 4.9 & 81 & 25.8 & 0.0004 \\
\hline & $>15$ days & 7 & 77.8 & 2 & 22.2 & 9 & 2.9 & \\
\hline & Total & 291 & 92.7 & 23 & 7.3 & 314 & 100 & \\
\hline
\end{tabular}

Concerning causes of admission to intensive care: pulmonary edema $82(26.1 \%)$, HELLP syndrome $57(18.2 \%)$ this is higher as compared to the study conducted in Singapore reported sever eclampsia and pulmonary edema accounted for $7.7 \%$ and $14.4 \%$ respectively (17). this differences may be due to low ANC follow ups, delayed arrival and setting difference which matters a lot about the management of this cases before some of the complications arises. Other study done in Argentina showed main causes of
ICU admission were eclampsia $(63 ; 34 \%)$, severe preeclampsia $(61 ; 33 \%)$, HELLP $(33 ; 18 \%)(14)$ Which is similar to this study finding in incidence of this complications and the percentage difference may be due to sample size difference between these studies.

About $26.1 \%$ women developed serious complications, of them $26.2 \%$ pulmonary edema, renal failure $24.3 \%$, and $19.2 \%$ coagulation problems and this is higher as compared to the study conducted in Yorkshire UK reported 13.9\% had serious 
complications including pulmonary edema(2.3\% of cases) (13). This rate of complication is much higher as compared to the study finding done in Spain in which complications rate was $14 \%$, of which $5 \%$ acute renal failure and $2 \%$ coagulopathy)(15),this higher rate of ICU maternal complication in our setting may be due the socio economic difference, JUSH ICU is not obstetric ICU it is general ICU that all patients from all over the departments within the hospital requiring ICU admission will be admitted and it has only six beds and two functioning ventilators for all admitted cases and this is a big challenge to provide necessary cares specially ventilator support in case the two functioning ventilators used by other patients.

This study finding is lower as compared to the study done in Cameroon which showed AKI (66.7\%), HELLP syndrome $(45.5 \%)$ and pulmonary edema $(18.2 \%)$ this may be due to the sample size ( $\mathrm{n}=78 \mathrm{vs} 314)$ difference setting difference(16) there is no dialysis and plasma exchange in our hospital setting and the complications were managed with supportive cares.

Regarding outcome- this study found maternal mortality of $7.3 \%$, which is higher when compared with study conducted in, Spain and Hong Kong china, reported $1.5 \%$ and $6 \%$, respectively $(15,17)$. The study conducted at University of Maiduguri Teaching Hospital Nigeria has showed the case fatality rate for eclampsia managed in ICU was $14.65 \%$ (18). The difference may be due to the difference in socio economic status of the countries which affects quality of medical care.

\section{Strengths and Limitations of This Study}

The strength of this study is the 5 years duration of study and large number of admitted cases studied. Furthermore, the results of this study will expectedly provide us with further knowledge on admission and outcome of preeclampsia and eclampsia patient at JUSH ICU.

The main limitations of this study include its retrospective design, single-center site, the inability to calculate population-based rates and cross sectional study is poor to show cause and outcome relationships and this study didn't explore the management of each cases.

\section{Conclusions and Recommendation}

Rate of maternal admission, complications and mortality is found to be high at JUSH ICU, Jimma University with other stakeholders has to work in improving high quality of cares provided to reduce maternal complications and mortality.

\section{List of Acronyms}

JUSH: Jimma University specialized hospital

ICU: Intensive Care Unit

HELLP syndrome: hemolysis, elevated liver enzymes and low platelet counts

AKI: Acute kidney injury
ANC: Antenatal care

\section{References}

[1] Casey E. Hayes N. Ross A. Obstetric critical care Clinical problems 2013. European Society of Intensive Care Medicine

[2] Public Health Agency of Canada. Make every mother and child count: report on maternal and child health in Canada. 2005. Available from: http://publications.gc.ca/collections/

[3] Jignesh J Kansaria, SV Parulekar Critical Care in Preeclampsia, Eclampsia Bombay Hospital Journal, Vol. 50, No. 1, 2008

[4] Cantwell R, Clutton-Brock T, Cooper G, and Dawson A, Drife J, Garrod D, et al. Saving Mothers' Lives: Reviewing maternal deaths to make motherhood safer: 2006-2008. The Eighth Report of the Confidential Enquiries into Maternal Deaths in the United Kingdom. BJOG 2011; 118 Suppl 1: 1-203. PMI D 21356004. http://www.hqip.org.uk/cmace-reports/

[5] Duckitt K, Harrington D. Risk factors for pre-eclampsia at antenatal booking: systematic review of controlled studies. BMJ 2005; 330(7491): 565. PMID 15743856

[6] Mirski MA, Varelas PN. Seizures and status epilepticus in the critically ill. Crit Care Clin 2008; 24(1): 115-147. PMID 18241782

[7] Karnad DR, Lapsia V, Krishnan A, et al. Prognostic factors in obstetric patients admitted to an Indian intensive care unit. Crit Care Med 2004;32:1294-9.

[8] Maine D, Chavkin W. Maternal mortality: global similarities and differences. J Am Med Womens Assoc 2002;57: 127-30.

[9] Bhattacharya S, Campbell DM. The incidence of severe complications of preeclampsia. Hyper tens Pregnancy. 2005; 24: 181-90.

[10] Soubra SH, Guntupalli KK. Critical illness in pregnancy: an overview. Crit Care Med 2005; 33(suppl):S248-S255

[11] Karnad DR, Guntupalli KK. Critical illness and pregnancy: review of a global problem. Crit Care Clin 2004; 20:555-576

[12] Gatt S. Pregnancy, delivery and the intensive care unit: need, outcome and management. CurrOpinAnaesthesiol 2003; $16: 263-267$

[13] D.J. Tuffnell et al. Outcomes of severe preeclampsia/eclampsia in Yorkshire 1999/2003 BJOG: an International Journal of Obstetrics and Gynecology July 2005, Vol. 112, pp. 875-880 www.blackwellpublishing.com/bjog

[14] Vasquez DN1, Neves AV2, Zakalik G3, Intile OS024. Characteristics and outcomes of critically ill obstetric patientswith hypertensive disease of pregnancy in argentina: Multicenter study.

[15] Curiel-Balsera E1, Prieto-Palomino MA, Muñoz-Bono J [Analysis of maternal morbidity and mortality among patients admitted to Obstetric Intensive Care with severe preeclampsia, eclampsia or HELLP syndrome].

[16] Eugene Belley Priso1, Theophile Nana Njamen1, Charlotte Nguefack Tchente1,2, Albert Justin Kana3, Trend in admissions, clinical features and outcome of preeclampsia and eclampsia asseen from the intensive care unit of the Douala General Hospital, Cameroon. 
[17] Leung NY, Lau AC, Chan KK, Yan WW. Clinical characteristics and outcomes of obstetric patients admitted to the Intensive Care Unit: a 10-year retrospective review Hong Kong Med J. 2010 Feb 16(1):18-25.

[18] Adamu Sadiq Abubakar1, 3, Mohammed Bukar2 ,Audit of Anaesthetic Management of Eclamptic Patients for Caesarean Section in the North-Eastern, Nigeria
[19] Nevra Alkanli1,Tammam Sipahi1, *, Tulay Okman Kilic2 ,Lack of association between ACE I/D and AGTR1 A1166C gene polymorphisms and preeclampsia in Turkish pregnant women of Trakya region 